\title{
Body image and disordered eating among LGBTQ+ university students and recent graduates in rural Appalachia: A thematic analysis
}

\author{
Devyn Savitsky \\ Department of Counseling and Higher Education \\ Ohio University, Athens, USA \\ E-mail: ds292216@ohio.edu.
}

Received: April 01, 2021; Revised: May 03, 2021; Accepted: May 07, 2021

\begin{abstract}
LGBTQ+ university students and recent graduates of a large rural Appalachian institution were interviewed for an exploratory thematic analysis on body image and disordered eating behaviors. While participants noted an overall sense of comfortability in the university setting, there were varying obstacles associated with navigating intersecting identities and physical presentation that were noted in the data. Excerpts from participant interviews were coded into five unique themes: (1) feeling "othered"/different from peers as well as fellow LGBTQ+ community members, (2) seeking comfortability with body/self, (3) facing stereotypes and image expectations based on presumed gender identity and/or sexual/affectional orientation, (4) general experiences as an LGBTQ + community member in a rural university town, and (5) seeking increased support from the university. This study concludes that significant challenges related to body image are exacerbated by common experiences as a person in the LGBTQ+ community.
\end{abstract}

Keywords: body image, eating disorder, LGBTQ+, college student, Appalachia, thematic analysis

This is an open-access article under the CC-BY-SA license.

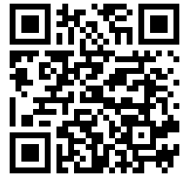

This is an open-access articleunder the cC-BY-SA license.

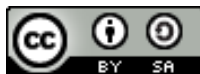

Introduction

Negative body image is so common that it often goes overlooked as a key aspect of one's sense of personal identity. According to Gallivan (2014), approximately $80 \%$ of women and $34 \%$ of men are dissatisfied with their bodies, $50 \%$ of Americans are unhappy with their current weight, $70 \%$ of women with a "normal" weight wish to be thinner, and over $80 \%$ of 10 year olds are "afraid of being fat" (pp. 3-4.) Negative body image is correlated with disordered eating, increased suicidality, and internalization of beauty and fitness ideals (Baker, Ferszt, \& Breines, 2019; The Trevor Project, 2018). Among members of the lesbian, gay, bisexual, transgender, queer/questioning and additional varying sexual/romantic and gender expansive identity (LGBTQ+) community, risk factors are significantly higher than in those that do not identify as lesbian, gay, bisexual, transgender, queer/questioning or any other sexual minority group for developing mental health problems including negative body image and/or disordered eating behaviors (Diemer, Grant, Munn-Chernoff, Patterson, \& Duncan, 2015; Dunbar, Sontag-Padilla, Ramchand, Seelam, \& Stein, 2017). A sense of connectedness to the LGBTQ+ community is related to fewer current eating disorders, which suggests that feeling connected to the LGBTQ+ 
community may have a protective effect against eating disorders (NEDA, 2018). Members of the LGBTQ + community living and studying in rural areas may face extra challenges in receiving support for body image concerns, healthcare, or generally as members of a larger community. For the purposes of this study, graduate students and a recent graduate from a large university in rural Appalachia were interviewed about their experiences as members of LGBTQ+ community members in terms of body image and sense of personal identity.

\section{Risk Factors for LGBTQ+ Individuals}

According to the National Eating Disorders Association (2018), LGBTQ+ people face unique challenges that may put them at greater risk of developing a negative body image and disordered eating behaviors than their cisgender, heterosexual/heteroaffectional peers. Potential risk factors that may play a role in the development of disordered eating behaviors and negative body image include: fear of rejection or experience of rejections by friends, family, and coworkers; internalized negative messages/beliefs about oneself due to sexual orientation, nonnormative gender expressions, or transgender identity; experiences of violence and posttraumatic stress disorder (PTSD); discrimination; bullying; discordance between one's biological sex and gender identity; and inability to meet body image ideals within some LGBTQ+ cultural contexts (NEDA, 2018).

Eating disorders continue to be the most fatal mental disorder with a mortality rate of about $10 \%$ as of 2011 (Arcelus, Mitchell, Wales, \& Nielsen, 2011). The number of individuals suffering with negative body image are significantly higher than the amount of LGBTQ+ individuals living with disordered eating, making disordered eating behavior development particularly concerning for the community as a whole. In addition to alarming statistics regarding rates of disordered eating and negative body image among members of the LGBTQ+ community, there are increased rates of depression and suicidality, as was reported in a survey conducted by The Trevor Project in partnership with the National Eating Disorders Association and Reasons Eating Disorder Center (2018). The aforementioned survey (The Trevor Project, 2018 ) indicated that the majority of LGBTQ+ youth (58\%) who reported having been diagnosed with an eating disorder said they had considered suicide. Between 85 and 96\% of LGBTQ+ youth diagnosed with an eating disorder have considered suicide with those living with bulimia nervosa having the highest rate of suicidal ideation. $66 \%$ of those who have considered suicide have been diagnosed with an eating disorder (The Trevor Project, 2018). In a national study conducted by James, Herman, Rankin, Keisling, Mottet, \& Anafi (2016), 40\% of transgender adults reported having made a suicide attempt; $92 \%$ of these individuals reported having attempted suicide before the age of 25 . Additionally, LGB youth seriously contemplate suicide at almost three times the rate of heterosexual youth (CDC, 2016). Negative body image, disordered eating, and suicidality are correlated and must be approached uniquely when working with members of the LGBTQ+ community regardless of age. Supportive school and home environments are seen as protective factors that reduce risk for LGBQ students (Ballard et al., 2017). In cases where body image is assessed to be a clinically significant concern for treatment, counselors should ask the client about the roles in which their communities (or lack of), romantic/sexual partners, family, friends, and important other people in the client's life may have played (Bozard et al., 2016).

\section{Being LGBTQ+ in Rural Appalachia}

Appalachia is defined as a region in the eastern United States, in the area of the southern Appalachian Mountains, usually including northeastern Alabama, northwestern Georgia, northwestern South Carolina, eastern Tennessee, western Virginia, eastern Kentucky, West Virginia, and southwestern Pennsylvania (Dictionary.com, n.d.) This particular study focuses on a 
large university in rural Appalachia. National Geographic (n.d.) defines a rural area as "an open swath of land that has few homes or other buildings, and a low population density." Rural community members are a particularly vulnerable group with higher rates of both obesity and depression, poor access to healthcare, and higher likelihood of unhealthy behaviors when compared to urban community members (Chang, Salas, Tabet, Kasper, Elder, Staley, \& Brownson, 2017). According to a study conducted by Ballard, Jameson, \& Martz (2017) in rural Appalachia, specifically, rural LGBQ youth are at a significantly higher risk than rural heterosexual youth for suicidality (five times more likely), bullying victimization, school violence, drug use, and sexual risk behavior. Additionally, Ballard et al. (2017) found that LGBQ students perceived a lower level of school and community support than heterosexual students, which consistent among LGBQ youth from urban, suburban, and rural areas. The needs of transgender students are addressed even less frequently than the needs of $\mathrm{LGBQ}+$ individuals in rural Appalachia, as many traditional Appalachian values prescribe to gender binaries assigned at birth and religious fundamentalism (Cooke-Jackson \& Hansen, 2008). Ballard et al. (2017) suggest developing preventative interventions for LGBQ youth that are built for rural environments.

\section{Being LGBTQ+ on a College Campus}

Understanding the impact of the campus environment on LGBTQ+ students' feelings of inclusion and acceptance is crucial in the success of students and colleges alike. College students - particularly members of the LGBTQ + community - are at high risk for mental health concerns. LGBTQ+ college students are specifically at risk of experiencing different forms of discrimination leading to isolation and avoidance (Evans, Nagoshi, Nagoshi, Wheeler, \& Henderson, 2017). Peer victimization prior to and during college is undoubtedly a risk factor for disordered eating behaviors and negative body image (Kwan, Gordon, Minnich, Carter, \& TroopGordon, 2017).

Many colleges and universities aim to welcome and respect diversity, particularly sexual/affectional minorities, but heterosexism can create a cold climate for sexual/affectional minority students on campus, as well as for those who identify as transgender or nonbinary (Woodford, Kulick, \& Atteberry, 2015). Although most sexual minority and transgender students persist, graduate from college, and live healthy lives, it is important to note that their journeys through a college experience are different than many of their cisgender, heteronormative peers (Woodford et al., 2015).

Making campuses welcoming and inclusive spaces for LGBTQ+ students is a priority for various universities within the United States. Many institutions utilize LGBT speakers, safe space programs, and other educational programs that aim to promote awareness, understanding, and acceptance of LGBTQ+ people on campus (Woodford et al., 2015). LGBTQ+ programs on campuses often focus on LGBTQ+ people as a separate, other group, rather than focusing on each identity and person individually leading to concerns that these programs are not based on a systematic understanding of campus climate for LGBTQ+ students (Woodford et al., 2015). The presence of faculty and staff that are more likely to confront anti-LGBTQ+, transphobic, or homophobic statements on campus creates a more positive perception of campus climate among the LGBTQ+ student population (Evanset al., 2017). Health-related resources could be designed for the general college student population; however, outreach and recruitment of students should be targeted towards LGBTQ+ students specifically (VanKim et al., 2016). When campus policies confirm the identities and unique needs of the LGBTQ+ community, they are less prone to minority stress and ultimately, less likely to live with debilitating negative body image and selfesteem due to the campus environment. 


\section{Body Image Concerns Among LGBQ+ Individuals}

In a survey conducted by The Trevor Project in partnership with the National Eating Disorders Association and Reasons Eating Disorder Center (2018), it was reported that of the $46 \%$ of LGBTQ youth surveyed who had not been diagnosed with an eating disorder, $54 \%$ reported that they suspected that they had an undiagnosed eating disorder. Body image distortion and disordered eating are important pediatric problems affecting individuals along the sexual orientation and gender identity spectrum (McClain, \& Peebles, 2016). In a study conducted by Diemer et al. (2015), results indicated that transgender and cisgender sexual minority young adults have elevated rates of compensatory behavior and self-reported eating disorder diagnosis.

Bozard \& Young (2016) describe the pressure exerted through gay culture to attain a lean, muscular appearance among sexual minority men. Gay males are thought to only represent 5\% of the total male population, but among males who have eating disorders, $42 \%$ identify as gay (NEDA, 2018). Current studies suggest that sexual minority males have increased body shape and weight dissatisfaction, anorexic and bulimic symptoms, and may consider physical appearance to be critical to their sense of self (McClain, \& Peebles, 2016). Coffey (2015) found that gay college men associate less muscular bodies with being too flamboyant or feminine. Additionally, sexual minority men are likely to experience cognitive dissonance as they seek social acceptance through their relationships while simultaneously receiving messages that their bodies do not meet cultural ideals from some of the same interpersonal relationships (Bozard et al., 2016). VanKim, Porta, Eisenberg, Neumark-Sztainer, \& Laska (2016) indicated in their study that nearly all men talked about the emphasis and pressure among gay males to have a particular physique or appearance and needing to be seen as sexually desirable to other gay men. Interpersonal experiences were found to be influential for sexual minority men's body image (Bozard et al., 2016).

Hayfield, Halliwell, \& Clarke (2017) discuss the false notion that lesbians may be immune to body image pressures and therefore have lower body dissatisfaction than heterosexual women. In a study by Baker et al. (2019), participants described a wide variety of beauty ideals that they have witnessed online including wearing makeup and/or using high quality makeup, being thin, having an hourglass-shaped body, as well as a fitness ideal (curvy, toned, and muscular) and wanted to meet these standards. Western cultures promote a thin and curvaceous ideal body size that most women find difficult to achieve by healthy measures, resulting in poor body image and increased risk for eating pathology (Smith, Telford, \& Tree, 2017). Smith et al. (2017) concluded that lesbian and bisexual women experienced similar mainstream pressures to conform to a thin body ideal. Hayfield et al. (2017) found that there were no significant differences between bodyesteem scores of bisexual, lesbian, and heterosexual women. Participants perceived additional pressure to conform to heteronormative standards of beauty (Smith et al., 2017).

\section{Body Image Concerns Among Transgender Individuals}

Transgender individuals report high levels of body dissonance and body image disturbances (Brewster, Velez, Breslow, \& Geiger, 2019). Diemer et al. (2015) suggest that using disordered eating behaviors to suppress or accentuate particular gendered features, minority stress, and a greater likelihood of contact with mental health professionals may be potential explanations for findings that transgender identity is associated with higher risk of self-reported eating disorder diagnosis and compensatory behavior. In addition to general body image concerns, transgender individuals face additional barriers in "achieving" the presentation that they desire (i.e. masculinity or femininity) (Brewster et al., 2019). Considering that, for many, a significant portion of the trans experience relates to perception of their bodies as it relates to 
identity, this population requires specific attention related and unrelated to the LGBQ+ community.

\section{Healthcare Needs for LGBTQ+ Individuals}

LGBTQ + healthcare needs are not being met in university health services (Hood, Sherrell, Pfeffer, \& Mann, 2019). According to Whitehead, Shaver, \& Stephenson (2016), LGBT adults are significantly less likely than non-LGBT adults to have a primary care physician and more likely to report being uninsured and unable to afford health services. This may be founded on expectations and experiences of stigma based on sexuality or gender identity. Transgender individuals are less "healthy" than the general population due to avoidance, discrimination, and feelings of social exclusion in primary and emergency care settings (Vermeir, Jackson, \& Marshall, 2018). Sexual orientation was identified as a stressor that adversely impacted physical activity and eating habits among college students, particularly noting that sexual orientation was either an added stressor or potential trigger for binge eating (VanKim et al., 2016). According to Dunbar et al. (2017), sexual minority students use mental health services at higher rates than non-sexual minorities but also have higher rates of unmet needs in their treatment.

In addition to sexual/affectional orientation and gender identity, it is important to address the impact of race/ethnicity on disordered eating behaviors and negative body image. According to Marques, Alegria, Becker, Chen, Fang, Chosak, \& Dinz (2011), the prevalence of anorexia nervosa and binge-eating disorder were similar across all groups examined, but bulimia nervosa was more prevalent among Latinx and Black individuals than non-Latinx White individuals. Lifetime prevalence of mental health service utilization was lower among ethnic minority groups studied than for White participants for respondents with a lifetime history of any eating disorder (Marques et al., 2011). The need for clinician and counselor training and health policy interventions are crucial in order to achieve equitable, high-quality healthcare for eating disorders across all ethnic groups in the United States (Marques et al., 2011).

Although there is a crucial need for universities to focus on the body image and identity development of their LGBTQ+ students, employees, and surrounding community members, these body image experiences do not always have to be negative. According to a study by VanKim et al. (2016), many members of the LGBTQ+ community felt their sexual orientation helped them be physically active, engage in healthful eating habits and have a positive body image. According to Woodford et al. (2015), physical exercise can help to reduce sexual minority students' stress and promote their physical and mental wellbeing, given the positive physiological, psychological, and neurological effects associated with exercise. Given the complexities of body image, disordered eating, and the positive reinforcement of physical wellness on mental health within the LGBTQ+ community, it is ever-important to hear from community members themselves about these issues and potential steps forward in creating a nourishing university environment.

\section{Research Method}

Upon receiving approval from the institutional review board (IRB) at the author's institution, a call for participation in an exploratory study on body image and disordered eating within the LGBTQ+ community was posted in a Facebook group for members of the LGBTQ+ community in Appalachia. The guiding research question of this study was: how do LGBTQ+ community members in a rural Appalachian college town describe their experiences with body image and disordered eating? Three members of the LGBTQ+ community in this region responded to the call and volunteered to be interviewed. 


\section{Participants}

As this was an exploratory study, there were three total participants. The author and reviewers believed that this small sample would be sufficient considering the overwhelming frequency at which members of this community are utilized and sometimes exploited for research purposes. Employment of a small sample size is said to enhance the validity of finegrained, in-depth inquiry (Crouch \& McKenzie, 2006). The three participants' ages ranged from 24 years of age to 31 years of age. The participants each identified as transgender/non-binary, woman, and man. Two participants described their sexual/affectional orientations as homosexual/homoromantic, and one participant described their sexual/affectional orientation as bisexual/biromantic. Two participants identified their race/ethnicity as White, and one participant described their race/ethnicity as Mexican-American (Latinx). Two of the three participants were student athletes during their undergraduate careers. All participants were enrolled in a graduate program or have graduated with a Master's degree within the last year. All participants of this study were living near the large Appalachian university at which the study was conducted for work or their education, and none were originally from that particular geographical area. Participants were asked to choose their own pseudonyms for this study in order to protect participant confidentiality, identify themselves in the manuscript, and to express their sense of personal identity on their own terms. The participants' names chosen for this study were Tamera (homosexual/homoromantic cisgender woman), Emory (bisexual/biromantic transgender/non-binary person), and Junior (homosexual/homoromantic cisgender man.) Participants were not offered compensation for their participation in this study.

\section{Procedures}

The author served as the interviewer for this study and made the decision that participants would receive a consent form without a signature with the primary reason being that signing a consent form may be seen as "outing" participants as members of the LGBTQ + community in Appalachia. Data was collected using in-depth, semi-structured qualitative interviews with three participants. All interviews began with asking permission to audio-record the interview and a discussion of demographic information. Each participant was interviewed once for 45 minutes to one hour. The author then completed verbatim transcriptions of each interview. All interviews took place in a counseling and research training facility located at an Appalachian university within a one-month period. Participants volunteered their time for these interviews and did not have prior relationships with the interviewer. Participant responses were reviewed and analyzed by the author who identifies as a member of the LGBTQ+ community and has had a history of disordered eating and negative body image, as well as by two Educational Studies faculty members at the author's institution.

\section{Methodology}

Thematic analysis (TA) is a method for identifying, analyzing, organizing, describing, and reporting themes found within a data set (Braun \& Clarke, 2006; Nowell, Norris, White, \& Moules, 2017). Participant responses were analyzed using Braun \& Clarke's (2006) six phase approach to TA; the phases include: (1) familiarizing oneself with the data, (2) generating initial codes, (3) searching for themes, (4) reviewing potential themes, (5) defining and naming themes, and (6) producing the report. The author conducted a thorough initial reading of the data and then went on to collect excerpts from the data as potential codes. Following ongoing analysis of data, establishing patterns, and generating themes, codes were created. The data was grouped based on themes and the author compared analyses with two faculty members. Where there was 100\% agreement among the author and faculty reviewers, the themes/codes remained; otherwise, the author and reviewers discussed the excerpts and reached a consensus on which codes would be most appropriate. 


\section{Findings and Discussion}

From the three participant narratives, thematic analysis segmentation produced 279 excerpts that were coded into themes and analyzed (Gagnon \& Roberge, 2012). A wide variety of conclusions were drawn about LGBTQ + community needs as they relate to unique body image experiences in a rural Appalachian university town. The themes noted in this study include: (a) feeling "othered"/different from peers as well as fellow LGBTQ+ community members, (b) seeking comfortability with body/self, (c) facing stereotypes and image expectations based on presumed gender identity and/or sexual/affectional orientation, (d) general experiences as an LGBTQ+ community member in a rural university town, and (e) seeking increased support from the university. Each participant noted that identifying as a member of the LGBTQ+ community impacts nearly every aspect of life in some capacity, making addressing overall experiences in the university setting key in discussing body image and disordered eating behaviors. A presentation of the results of this study and sample participant narratives are presented in Table 1.

Table 1. Segments of participant collaborative experiences from most to least represented

Themes Frequency of Occurrence
Sample Participant Narratives
"Othering"/differences from peers

Seeking body comfortability
"I never had a thought that somebody else was maybe gay, too. Like, I think I was, in my world, probably the only one who had these thoughts"

"Watching other boys in gym class was always, like, this experience of socializing that I just observed and I was never going to be a part of."

"I have to go to [larger Appalachian city] to feel like I'm not in a closet. I feel like the 'real world' is [larger Appalachian city], or at least the 'real world' that I want to experience and hope to be a part of. If I were in [larger Appalachian city] maybe I wouldn't be the only one that expressed themself in a [fun] shirt."

"Most of the time I'm pretty comfortable with who I am and how my body is. But... I'm not every single day. It's no different for anybody else whether or not they identify as LGBT or heteronormative. Just because I'm not as feminine and don't want to do a lot of makeup doesn't mean I'm not concerned about my appearance."

"What my body image has shifted to has been a tug of war between the internalized stuff that I have and that part of my body 
image kind of, you know, telling me 'you're bad, you were better when you were 14 , you shouldn't be like this' versus the part that I'm really working to support, which is 'my body can do some really amazing things.' And yeah, there's some things that, because of dysphoria or because of whatever, that I wish were a little bit different but, you know, I can change those things if I want to and that's okay. I'm my own kind of beautiful and my own kind of unique."

"People assume that a lot of LGBT people are either, like, super healthy or on the complete other end of the spectrum and just don't care about how they treat their body."

"It's not like how the media presents it where it's like, 'okay, everyone that's part of this community is just born in the wrong body and they hate themselves all their lives, and then they get 'the surgery' and then they're fine, and everything's great and peachy and they're never unhappy again.' That very specific narrative that people get told is super not accurate, I think, for most of us. Not everyone has the same issues with the same parts of their body."

"Another thing is whenever you think about, specifically, nonbinary/trans people or gender non-conforming/trans people, a lot of times the picture that people get in their head is, like, this skinny, White, perfectly androgynous person, and that's not the case for most people. It's hard to be androgynous when you're bigger."

"Being gay means you have to be better or have this Adonis body. I wonder if in the end it is this hyper masculine, athletic, heteronormative thing that we're all chasing."

"People are welcoming to the standard lesbian and gay... but, I think I would have a much different experience if I identified differently on the spectrum." 
Need for increased support
"I tend to feel better about my body image whenever I'm around people here. It's interesting because I actually work about 45 minutes away and that's a bit of a different environment. That's definitely not as accepting of an environment either towards LGBT people or even just in general about body image... I'm not safe to be out there."

"I've definitely gotten a lot firmer in my sense of identity here."

"It's really hard to meet someone here. I think, like, especially thinking in terms of friends or dating. You have to really, I think, put yourself out there and risk outing yourself."

"Another time that I was out with friends, we were waiting in line talking and this student kept saying 'gay...gay' and it would get louder... It was like, is this really happening? It's just something that's always stayed with me."

"We are, like, the poorest county in [redacted Appalachian state]. Outside of the university life, not everyone is educated or understands what it means to be trans and it's not their fault because they don't have access to those resources."

"I went to [the campus health center] for something unrelated... I put my pronouns on the forms, and they never really acknowledged it. There's a possibility that I would probably have to travel to places like [larger Appalachian cities] to get the kind of healthcare that I need."

"Being in [a supportive] environment-- it's easier to get a handle on your own sense of self and your own sense of value."

"Trying to provide more access or resources or just doing different events within the surrounding community, not just, like, on campus. Even when it is not just for students but for community, we're 
still limiting so many people outside that could benefit."

"With programming at the school, there's been, like, female speakers that come talk about body image or eating... but, tuning into narratives of males that also have body image concerns or relationships with food, etc. [would be helpful.] We're a community, and so we should hear those stories."

Total number of excerpts:

Table 1 represents the most common themes that emerged from the data and a selection of excerpts that illustrate some of the perceptions on body image that the participants put forward. Theme (a) feeling "othered"/different from peers as well as fellow LGBTQ+ community members explores excerpts on experiences with isolation, conflicting messages about self presentation, and the impact of "traditional, small town" upbringings on self esteem and body image. There were 80 coded items related to this theme, making feelings of isolation and difference from peers the most important factor in body image development and maintenance for the LGBTQ+ community in this rural Appalachian university setting. Theme (b) seeking comfortability with body/self addresses ongoing use of local resources and mental health support, perspectives on improving body image, attempting to accept one's body as is, and acknowledgment that each person's body image journey is personal. As the theme with the second highest number of coded items, it can be inferred that this group of participants valued direct confrontation of body image concerns through counseling or other support systems. Theme (c) facing stereotypes and image expectations based on presumed gender identity and/or sexual/affectional orientation works to address expectations about body image, common misconceptions about LGBTQ+ bodies that may be harmful to this community as a whole. This theme addresses the difficulties that come with continuously facing preconceived notions based on both sexual/affectional orientation and physical presentation. Theme (d) general experiences as an LGBTQ+ community member in a rural university town focuses on social opportunities, differences in experiences on and off campus, desire to find companionship in more populated areas, and instances of harassment. Theme (e) seeking increased support from the university is the theme with the least amount of codable items. Though the final theme includes just 27 excerpts from the data, this theme is of the utmost importance as universities strive to improve student, faculty/staff, and community experiences. This theme reinforces the necessity to improve community programming, increase education opportunities that address body image and disordered eating as well as LGBTQ+ issues, and to make active efforts to improve general health and mental healthcare services.

\section{Conclusion}

It is crucial that local organizations, universities, and community groups provide resources for community members educating them on LGBTQ+ issues in order to provide a safe environment for those native to the area and those moving to the area for school or work. Because eating disorders and negative body image are so pervasive among members of the LGBTQ + community, it is critical that a university and its surrounding community work together to provide a supportive space to address these responsibilities. A supportive community 
could certainly serve as a protective factor to reduce disordered eating and negative body image risk among queer university students. This supportive community must include all mental and physical healthcare professionals in the university setting as a minimum standard. Allowing local organizations and student groups to build a strong sense of community and support is seemingly the easiest way to prevent the spread of disordered eating and negative body image among this community. Through a safe, affirming university environment, universities can make strides toward drastically improving body image and disordered eating behaviors among LGBTQ+ community members.

\section{References}

Arcelus, J., Mitchell, A. J., Wales, J., \& Nielsen, S. (2011). Mortality rates in patients with anorexia nervosa and other eating disorders: a meta-analysis of 36 studies. Archives of general psychiatry, 68(7), 724-731. doi: 10.1001/archgenpsychiatry.2011.74

Baker, N., Ferszt, G., \& Breines, J. G. (2019). A Qualitative Study Exploring Female College Students' Instagram Use and Body Image. Cyberpsychology, Behavior, and Social Networking. https://doi.org/10.1089/cyber.2018.0420

Ballard, M. E., Jameson, J. P., \& Martz, D. M. (2017). Sexual identity and risk behaviors among adolescents in rural Appalachia. Journal of Rural Mental Health, 41(1), 17-29. https://doi.org/10.1037/rmh0000068

Bozard Jr, R. L., \& Young, J. S. (2016). The roles of family, friends, and romantic/sexual partners in the body image of sexual minority men. Journal of Counseling \& Development, 94(2), 150160. https://doi.org/10.1002/jcad.12072

Braun, V., \& Clarke, V. (2006). Using thematic analysis in psychology. Qualitative Research in Psychology, 3(2), 77-101. doi: 10.1191/1478088706qp063oa

Brewster, M. E., Velez, B. L., Breslow, A. S., \& Geiger, E. F. (2019). Unpacking body image concerns and disordered eating for transgender women: The roles of sexual objectification and minority stress. Journal of counseling psychology, 66(2), 131-142. https://doi.org/10.1037/cou0000333

CDC. (2016). Sexual Identity, Sex of Sexual Contacts, and Health-Risk Behaviors Among Students in Grades 9-12: Youth Risk Behavior Surveillance. Atlanta, GA: U.S. Department of Health and Human Services. https://www.cdc.gov/mmwr/volumes/65/ss/pdfs/ss6509.pdf

Chang, J. J., Salas, J., Tabet, M., Kasper, Z., Elder, K., Staley, H., \& Brownson, R. C. (2017). Changes in body mass index and the trajectory of depressive symptoms among rural men and women. The Journal of Rural Health, 33(2), 190-197. doi: 10.1111/jrh.12170

Coffey, D. E. (2015). Effect of Targeted LGBT Media on Body Image Perception Of Gay College Men (Doctoral dissertation). http://hdl.handle.net/11714/594

Cooke-Jackson, A., \& Hansen, E. K. (2008). Appalachian culture and reality TV: The ethical dilemma of stereotyping others. Journal of Mass Media Ethics, 23(3), 183-200. https://doi.org/10.1080/08900520802221946

Crouch, M., \& McKenzie, H. (2006). The logic of small samples in interview-based qualitative research. Social Science Information, 45(4), 483-499. https://doi.org/10.1177/0539018406069584

Diemer, E. W., Grant, J. D., Munn-Chernoff, M. A., Patterson, D. A., \& Duncan, A. E. (2015). Gender identity, sexual orientation, and eating-related pathology in a national sample of college students. Journal of Adolescent Health, 57(2), 144-149. doi: 10.1016/j.jadohealth.2015.03.003

Dunbar, M. S., Sontag-Padilla, L., Ramchand, R., Seelam, R., \& Stein, B. D. (2017). Mental health service utilization among lesbian, gay, bisexual, and questioning or queer college students. Journal Adolescent Health, 61(3), 294-301. https://doi.org/10.1016/j.jadohealth.2017.03.008 
Evans, R., Nagoshi, J. L., Nagoshi, C., Wheeler, J., \& Henderson, J. (2017). Voices from the stories untold: Lesbian, gay, bisexual, trans, and queer college students' experiences with campus climate. Journal of Gay \& Lesbian Social Services, 29(4), 426-444. https://doi.org/10.1080/10538720.2018.1378144

Gagnon, L. L., \& Roberge, G. D. (2012). Dissecting the journey: Nursing student experiences with collaboration during the group work process. Nurse Education Today, 32(8), 945-950. https://doi.org/10.1016/j.nedt.2011.10.019

Gallivan, H.R. (2014). Teens, social media, and body image. Retrieved February 10, 2019 from https://www.macmh.org/wp-content/uploads/2014/05/18_Gallivan_Teens-socialmedia-b ody-image-presentation-H-Gallivan-Spring-2014.pdf

Hayfield, N., Halliwell, E., \& Clarke, V. (2017). An exploration of bisexual, lesbian, and heterosexual women's body dissatisfaction, and body hair and make-up practices. Psychology of Sexualities Section Review, 8(2), 55-67. https://uwerepository.worktribe.com/output/876810

Hood, L., Sherrell, D., Pfeffer, C. A., \& Mann, E. S. (2019). LGBTQ College Students' Experiences With University Health Services: An Exploratory Study. Journal of homosexuality,66(6), 797-814. https://doi.org/10.1080/00918369.2018.1484234

James, S. E., Herman, J. L., Rankin, S., Keisling, M., Mottet, L., \& Anafi, M. (2016). The Report of the 2015 U.S. Transgender Survey. Washington, DC: National Center for Transgender Equality. https://www.transequality.org/sites/default/files/docs/USTS-Full-ReportFINAL.PDF

Kwan, M. Y., Gordon, K. H., Minnich, A. M., Carter, D. L., \& Troop-Gordon, W. (2017). Peer victimization and eating disorder symptoms in college students. Journal of social and clinical psychology, 36(5), 419-436. https://doi.org/10.1521/jscp.2017.36.5.419

Marques, L., Alegria, M., Becker, A. E., Chen, C.-n., Fang, A., Chosak, A., \& Diniz, J. B. (2011). Comparative prevalence, correlates of impairment, and service utilization for eating disorders across US ethnic groups: implications for reducing ethnic disparities in health care access for eating disorders. International Journal of Eating Disorders, 44(5), 412-4120. doi: 10.1002/eat.20787

McClain, Z., \& Peebles, R. (2016). Body image and eating disorders among lesbian, gay, bisexual, and transgender youth. Pediatric Clinics, 63(6), 1079-1090. doi: 10.1016/j.pcl.2016.07.008

National Eating Disorders Association. (2018, February 21). Eating disorders in LGBTQ populations. https://www.nationaleatingdisorders.org/learn/general-information/lgbtq

National Geographic (n.d.) Rural area. National Geographic. Retrieved from https://www.nationalgeographic.org/encyclopedia/rural-area/

Nowell, L. S., Norris, J. M., White, D. E., \& Moules, N. J. (2017). Thematic analysis: Striving to meet the trustworthiness criteria. International Journal of Qualitative Methods, 16(1). https://doi.org/10.1177/1609406917733847

Smith, M. L., Telford, E., \& Tree, J. J. (2017). Body image and sexual orientation: The experiences of lesbian and bisexual women. Journal of Health Psychology, 24(9), 1178-1190. https://doi.org/10.1177/1359105317694486

The Trevor Project. (2018). Eating disorders among LGBTQ youth: A 2018 national assessment. https://www.thetrevorproject.org/wpcontent/uploads/2018/03/Suicidality-and-EatingDis orders-Among-LGBTQYouth-2018-2.pdf

VanKim, N. A., Porta, C. M., Eisenberg, M. E., Neumark-Sztainer, D., \& Laska, M. N. (2016). Lesbian, gay and bisexual college student perspectives on disparities in weight-related behaviours and body image: a qualitative analysis. Journal of Clinical Nursing, 25(23-24), 3676-3686. doi: 10.1111/jocn.13106

Vermeir, E., Jackson, L. A., \& Marshall, E. G. (2018). Barriers to primary and emergency healthcare for trans adults. Culture, Health \& Sexuality, 20(2), 232-246. https://doi.org/10.1080/13691058.2017.1338757 
Whitehead, J., Shaver, J., \& Stephenson, R. (2016). Outness, stigma, and primary health care utilization among rural LGBT populations. PloS one, 11(1), e0146139. https://doi.org/10.1371/journal.pone.0146139

Woodford, M. R., Kulick, A., \& Atteberry, B. (2015). Protective factors, campus climate, and health outcomes among sexual minority college students. Journal of Diversity in Higher Education, 8(2), 73. doi: 10.1037/a0038552. 